\section{Late stent malapposition combined by thrombus resolution after primary stenting in acute myocardial infarction: Optical coherence tomography findings}

\author{
Akut miyokart enfarktüsünde primer stentleme \\ sonrası geç stent malapozisyonu ile birlikte trombüs \\ resolüsyonu
}

\section{Introduction}

The late stent malapposition (LSM) is defined as a separation of the stent struts from the intima of the coronary artery wall which was not present just after implanting the stent. Although drug-eluting stents (DESs) dramatically reduce the in-stent restenosis, several studies have reported a higher frequency of LSM on follow-up intravascular ultrasound (IVUS) examination after DES implantation compared with bare metal stents (1). Several postulated mechanisms of LSM after DES implantation have been suggested, but the mechanisms and clinical impact of LSM have not been clear.

We report a case of LSM after primary DES implantation and the optical coherence tomography (OCT) was used to confirm stent malapposition combined by thrombus resolution.

\section{Case Report}

A 68-year-old man underwent percutaneous coronary intervention (PCI) because of non-ST elevation myocardial infarction (NSTEMI). The initial coronary angiography (Fig. 1A) showed total occlusion of proximal right coronary artery (RCA). After ballooning, the angiography in the RCA (Fig. 1B) revealed diffuse thrombi through proximal to distal segment. Three paclitaxel-eluting stents (Taxus; $4.0 \times 28 \mathrm{~mm}, 3.5 \times 38 \mathrm{~mm}, 2.75 \times 38$ $\mathrm{mm}$ ) were implanted with high pressure in the RCA. After successful stents implantation, the final coronary arteriogram (Fig. 1C) revealed no residual stenosis, dissection or aneurysm in the stented segment of RCA. We performed examinations at 9 months after stents implantation. Follow-up coronary angiography (Fig. 1D) showed no significant stenosis in the RCA, but there was an aneurysmal change at distal stented segment of RCA. And then, the IVUS (Fig. 2A) and OCT images (Fig. 2B) clearly demonstrated markedly malapposed struts of stent at distal RCA. Also, the OCT images (Fig. 2C) showed stent malapposition combined by thrombus resolution as well as good apposition with fulfilled thrombus which had not been detected by coronary angiography and IVUS.

\section{Discussion}

Several studies have reported LSM was common after DES than after bare metal stent implantation (2). Currently, the various postulated mechanisms of LSM have been reported. Potential mechanisms of LSM include vessel enlargement, stent recoil, thrombus resolution behind the struts, and plaque shrinkage (3). Previous studies have shown that the main cause of LSM was positive remodeling without an equal amount of peristent neointimal hyperplasia or plaque growth so that the vessel pulled away from the stent without tissue fill-in; thrombus resolution so that a gap formed between the stent and the vessel wall was a potential mechanism after primary stenting in acute myocardial infarction (AMI) $(4,5)$.

In this case, the OCT images showed stent malapposition combined by thrombus resolution as well as good apposition with fulfilled thrombus after primary stenting. These findings support the importance of thrombus resolution as a mechanism of LSM. Because these findings had not

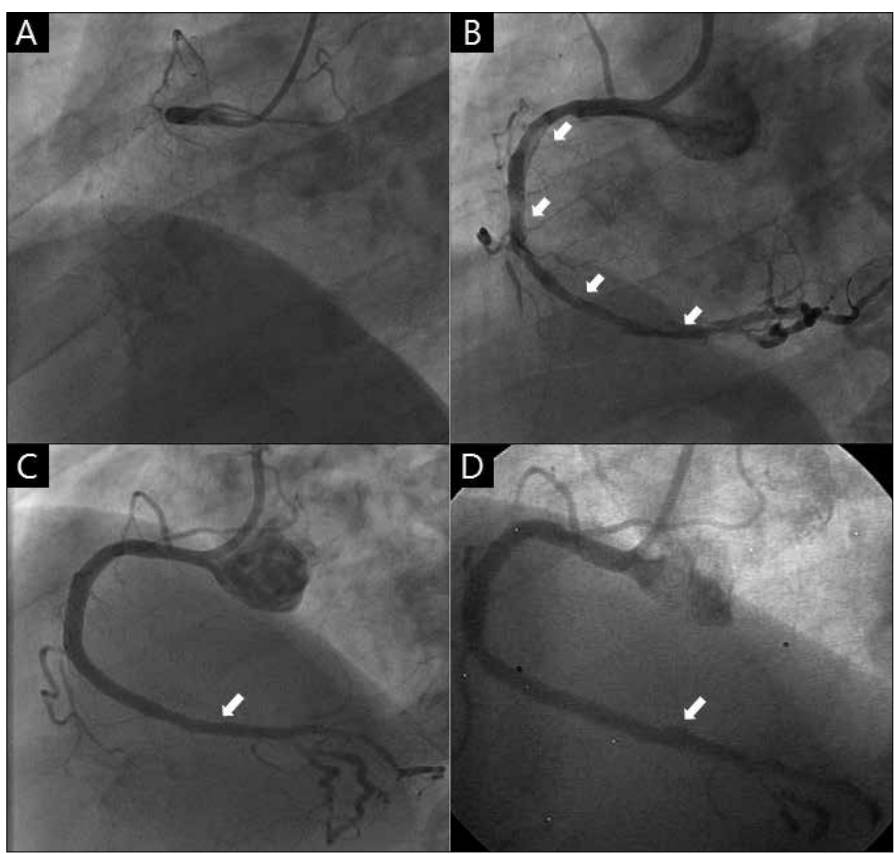

Figure 1. A) The initial coronary angiography shows total occlusion of right coronary artery (RCA) B) The coronary angiography after ballooning shows diffuse thrombi through proximal to distal segment of RCA (white arrows) C) The coronary angiography after stenting shows no significant luminal narrowing at the site of thrombus revealed previously (white arrow) D) This follow-up coronary angiography at 9 months after stents implantation shows an aneurysmal change at the distal segment of RCA (white arrow)

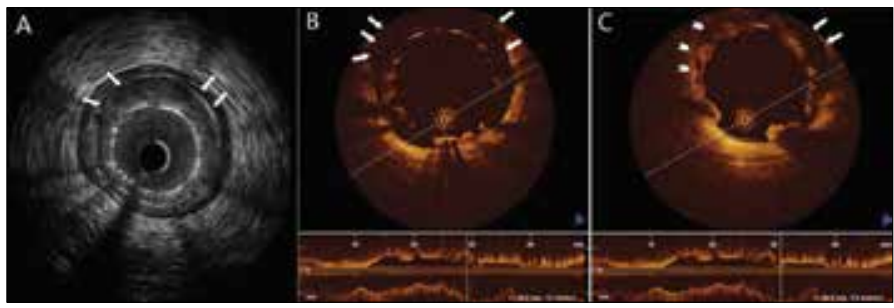

Figure 2. A) This intravascular ultrasound (IVUS) image shows stent malapposition at the distal RCA (white arrows) B) This optical coherence tomography (OCT) image shows markedly malapposed part of stent (white arrows) C) This OCT image shows stent malapposition combined by thrombus resolution (white arrows) and good apposition with fulfilled thrombus (white arrow heads)

been detected by coronary angiography and IVUS, the OCT images gave more information than that of coronary angiography and IVUS.

The relationship between LSM and long-term clinical outcomes remains controversial (6). Cook et al. (7) demonstrated that patients with very late stent thrombosis showed positive arterial remodeling with a high incidence of stent malapposition. It has been speculated that LSM may serve as a local nidus for thrombus formation by allowing fibrin and platelet deposition (8). However, the careful follow-up for the lesion detected thrombus previously will be required because of the substantial complications.

\section{Conclusion}

We presented a case of LSM combined by thrombus resolution evaluated by OCT after primary DES implantation in AMI. Our findings can be the important evidence that one potential mechanism of LSM is the absorption of previous thrombi. 
Ae-Young Her, Jung-sun Kim', Yong Hoon Kim, Donghoon Choi', Myeong-Ki Hong', Yangsoo Jang'

Division of Cardiology, Department of Internal Medicine, School of Medicine, Kangwon National University, Chuncheon-Republic of Korea 1Division of Cardiology, Yonsei Cardiovascular Center, Yonsei University College of Medicine, Seoul-Republic of Korea

\section{References}

1. Kang SJ, Mintz GS, Park DW, Lee SW, Kim YH, Lee CW, et al. Late and very late drug-eluting stent malapposition: serial 2-year quantitative IVUS analysis. Circ Cardiovasc Interv 2010; 3: 335-40. [CrossRef]

2. Hassan AK, Bergheanu SC, Stijnen T, , van der Hoeven BL, Snoep JD, Plevier JW, et al. Late stent malapposition risk is higher after drug-eluting stent compared with bare-metal stent implantation and associates with late stent thrombosis. Eur Heart J 2010; 31: 1172-80. [CrossRef]

3. Kalinczuk L, Pregowski J, Mintz GS, Dilcher CE, Kotani J, Kruk M, et al. Incidence and mechanism of late stent malapposition after phosphorus-32 radioactive stent implantation. Am J Cardiol 2003; 92: 970-2. [CrossRef]

4. Hong MK, Mintz GS, Lee CW, Park DW, Park KM, Lee BK, et al. Late stent malapposition after drug-eluting stent implantation: an intravascular ultrasound analysis with long-term follow-up. Circulation 2006; 113: 414-9. [CrossRef]
5. Shah VM, Mintz GS, Apple S, Weissman NJ. Background incidence of late malapposition after bare-metal stent implantation. Circulation 2002; 106: 1753-5. [CrossRef]

6. Siqueira DA, Abizaid AA, Costa Jde R, Feres F, Mattos LA, Staico R, et al. Late incomplete apposition after drug-eluting stent implantation: incidence and potential for adverse clinical outcomes. Eur Heart J 2007; 28: 1304-9. [CrossRef]

7. Cook S, Wenaweser $P$, Togni $M$, Billinger $M$, Morger $C$, Seiler $C$, et al Incomplete stent apposition and very late stent thrombosis after drugeluting stent implantation. Circulation 2007; 115: 2426-34. [CrossRef]

8. Waksman R. Late thrombosis after radiation. Sitting on a time bomb. Circulation 1999; 100: 780-2. [CrossRef]

Address for Correspondence/Yazışma Adresi: Jung-Sun Kim, MD, PhD, Division of Cardiology, Yonsei Cardiovascular Center, Yonsei University College of Medicine, 120-752, Shinchondong, Seodaemun-gu,

Seoul-South Korea

Phone: 82-2-2228-8460

E-mail: kjs1218@yuhs.ac

Available Online Date/Çevrimiçi Yayın Tarihi: 27.05.2013

(c) Telif Hakkı 2013 AVES Yayıncılık Ltd. Şti. - Makale metnine www.anakarder.com web sayfasından ulaşılabilir.

(c) Copyright 2013 by AVES Yayıncllk Ltd. - Available online at www.anakarder.com doi:10.5152/akd.2013.149 